\title{
DIFFICULT LARYNGOSCOPY AND TRACHEAL INTUBATION DUE TO CALCIFIED STYLOHYOID LIGAMENTS
}

\author{
O.O. AKinyemi and E.O. Elegbe.
}

\begin{abstract}
Two cases of difficult laryngoscopy and tracheal intubation caused by calcified stylohyoid ligaments are presented. Neither patient exhibited a skin crease over the hyoid bone. It is suggested that inability to lift up the epiglottis from the posterior pharyngeal wall be taken as a more useful sign of this condition than the presence of the skin crease.
\end{abstract}

KEy WORDS: ANATOMY; larynx, Tracheal IntUBATION, complications, calcified stylohyoid ligaments.

ONE OF THE unexpected causes of difficult tracheal intubation is calcified stylohyoid ligament, as reported in 1976 by Sharwood-Smith. ${ }^{1}$ The presence of a recognisable skin crease over the hyoid bone was suggested as a warning sign. Recently, however, we came across two cases of difficult laryngoscopy and tracheal intubation. On investigation, both patients were found to have calcified stylohyoid ligaments without an external skin crease over the hyoid. These are presented to show that this sign is not invariably associated with stylohyoid calcification.

\section{CAse 1}

A healthy female aged 36 years was admitted to hospital for ligation of both fallopian tubes. That was her first ever hospital admission and she had not had any anaesthetic in the past. With the patient in the 'sniffing the morning air' position, anaesthesia was induced with thiopentone $250 \mathrm{mg}$ and suxamethonium bromide $67 \mathrm{mg}$ intravenously. Several attempts at laryngoscopy with a Macintosh blade and intubation with the aid of metal stylet in the tube failed. The epiglottis was observed to be resting against the posterior pharyngeal wall from which it was impossible to lift it with the tip of the laryngoscope blade lying in the vallecula. The operation was abandoned then, but was successfully completed a week later under anaesthesia with nitrous oxide and halothane delivered by face mask.

Careful examination of the patient's neck failed to reveal a skin crease over the hyoid bone, but on

O.O. Akinyemi, M.B.B.S., F.F.A.R.C.S., F.M.C.A., F.W.A.C.S., E.O. Elegbe, M.B.B.S., F.F.A.R.C.S.I., D.A. Department of Anaesthesia, University College Hospital, Ibadan, Nigeria.

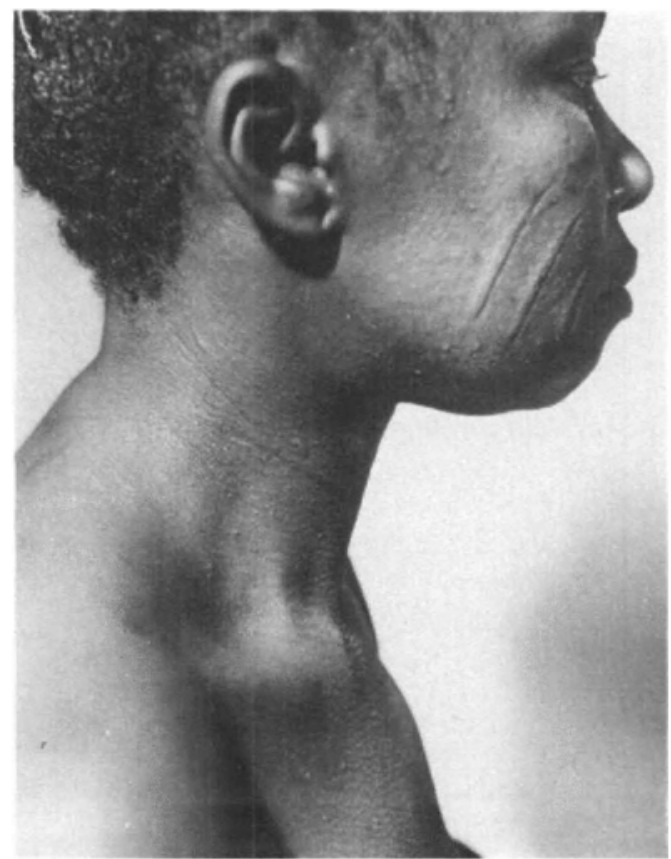

FIGURE I Photograph of the patient's neck showing absence of deep skin crease over the stylohyoid ligament.

radiographic examination, both stylohyoid ligaments were found to be calcified (Figures $I$ and 2).

\section{CAse 2}

A 50-year-old male patient was scheduled for excision of a small pharyngeal tumour found from a previous biopsy to be a pleomorphic adenoma of the mandible. Anaesthesia was induced with thiopentone $250 \mathrm{mg}$ and a total of $268 \mathrm{mg}$ of 


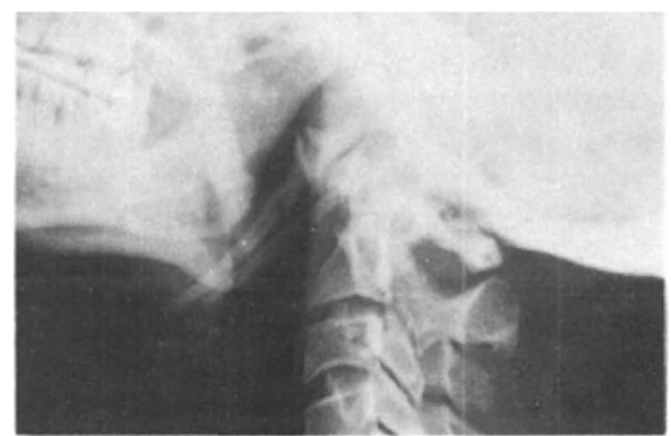

FIGURE 2 X-ray of the neck showing calcified stylohyoid ligaments.

suxamethonium bromide $(67 \mathrm{mg}$ in each of four doses). Laryngoscopy with a Macintosh blade revealed an epiglottis, not displaced by the tumour, but again difficult to lift away from the posterior pharyngeal wall. Eventually, spontaneous breathing of halothane with nitrous oxide and oxygen from a face mask was continued to a deep level of anaesthesia. Laryngoscopy was repeated and a 'dimple' through which respiratory gases were being expired was used to guide the tube with stylet into the trachea. This was accomplished with some difficulty.

Careful examination of the neck again revealed no external skin crease over the stylohyoid ligament, but radiographic examination showed calcification of both stylohyoid ligaments.

\section{Discussion}

The common causes of difficult tracheal intubation have been well documented, ${ }^{2}$ and most of them can be anticipated after a well conducted pre-operative visit to the patient. Occasionally, however, there is either no past history or record of difficult intubation of the trachea, or there is no external warning sign. Moreover, in emergency cases, there may be inadequate time to discover some of these signs, In the case of a calcified stylohyoid ligament, which is a common incidental finding, ${ }^{3}$ a skin crease was suggested as a useful warning sign. However, it appears to us that the commonest feature in our two cases and in the one reported by Sharwood-Smith is the difficulty of lifting the epiglottis from the posterior pharyngeal wall with the curved laryngoscope blade to reveal the vocal cords. To us this is a more constant warning sign than is the external skin crease, which may be absent, as in our two cases. The cause of the difficulty is a splinting effect of the calcified ligament on the adjacent soft tissues. This inability to lift up the epiglottis irrespective of its cause should prompt the Anaesthetist to consider the following steps:

(1) use of a stylet;

(2) the use of a straight laryngoscope blade;

(3) spontaneous respiration and use of the guidance of the expired gases passing through the tube to track the tube and stylet into the trachea;

(4) guided blind intubation ${ }^{4}$ or use of an intubating laryngoscope.

\section{REFERENCES}

I. Sharwood-Smith, G.H. Difficulty in intubation. Calcified stylohyoid ligament.Anaesthesia, 3I: 508 (1976).

2. CASS, N.M., JAMES, N.R. \& LiNEs, V. Difficult direct laryngoscopy complicating intubation for Anaesthesia. Brit. Med. J., I: 488 (1956).

3. LAST, R.J. Anatomy Regional and Applied, Sth Edn. p. 615 London, Churchill Livingstone (1972).

4. WATERS, D.J. Guided blind endotracheal intuba. tion for patients with deformities of the upper jaw. Anaesthesia, 18: 158 (1963).

\section{RÉSUMÉ}

Les auteurs rapportent deux cas de laryngoscopie et d'intubation difficiles causés par la présence d'un ligament stylohyoïdien calcifié. Ni l'un ni l'autre des patients ne présentaient le pli cutané au-dessus de l'os hyoide décrit dans de tels cas. L'incapacité de soulever l'épiglotte de la paroi pharyngée postérieure semble un meilleur signe pour détecter ces conditions. 